\title{
Plant layout design and assessment consideration of cellular manufacturing system via G.A
}

\author{
Dhurgham Aiham Kadhim Alshakarchi \\ Maytham Salman azeez \\ Univ. Al- Kafeel College Technical computer engineering \\ durghamalshakerchi@gmail.com \\ maytham.jebory@gmail.com
}

Recived : $14 \backslash 8 \backslash 2017$

Revised : 29\8\2017

Accepted : 1319\2017

\begin{abstract}
Cellular manufacturing is a wide world and many study and researches discussed are concerning with it because of the large demand in market and wheel technology push the scientist to find tools that can stand with this fast change in demand according specific market, so that they invent the best way to deal with optimization purpose. In this research the dealing with cellular optimization in such a way that can be manageable by AI and using type of AI that named natural optimization. The applying of genetic algorithms was carried out on factory of electrical motor also all data was taken from the factory which is depend on the position and sequence of operations took place in the factory. The theory in this field were also taking in consideration and the applications was carried out . the research deals with problem in two way theoretically that can take in consideration the positions of machines inside the plant and its equations that covers with some constraints and the secondly the routing of part during product life cycle and execute results and applying it on factory configuration. There are multi solutions (results) in the research for the problem that can achieve the flexibility, simplicity and also desired distance
\end{abstract}

Keyword: Cellular manufacturing , Genetic Algorithms , optimization, layout 


\subsection{Introduction}

Cellular manufacturing system (CMS) it is one of Group technology which it analyzes manufacturing system into subsystems to make it more easier for managing rather than the manufacturing system itself. In such a system, parts are grouped according to its features and manufacturing process so Part are grouped based on similar process or machining needed for final product Therefore, the important tasks of designing CMS is to identify similarity between parts (families) and their related machines (cells) which can be known as cell formation problem (CFP). The partitions of CF are a set of parts into peculiar part types which means that parts of same family are similar in terms of exterior, production process requirements, flow of materials, etc. A assigning manufacturing cells or in the other hand assigning part to each related machine all the production process requirements of the corresponding part family such as machines, tools, manpower, etc. It has been shown that CMS is a suitable solution to the problem of productivity in a batch production environment which is used in $50-75 \%$ of manufacturing systems worldwide [1]. The main goal in CMS is the principle of "Similar things should be done similar procedure "which means the similar manufacturing processes and features should be stated and collected in same identified manufacturing cells.

\subsection{Genetic Algorithms}

Genetic algorithms it's a technique for optimization purposes. Its inspirited depending on evolution theory "survival fitness". Searching on best suitable solution in feasible possible region which mean you don't require for any possible solution in the feasible region to obtain a satisfying result. G.A. is established on the evolutionary process. In nature, the fittest individuals like to revive and mate; for that reason the next generation will more fitter and improved because they were bred from better parents. This same concept is applied to solve problems concerning designing plant layout or scheduling[3].

\subsection{Review}

Here is some short literature survey of some scientist in same field and their contributions and research on G.A. will be beneficial if we narrative their work briefly .

[ Liang Sun \& etal] in this research they present retribution function in scheduling of job shop and they present in the progression of research an algorithms that has ability of election descendants according to moreover mutation and they present new strategy for Immortalize life span. During the research they design an adaptive algorithms can be used in both feasible and non-feasible region and simulate in twenty four bench mark.

[Zlatan Car \& Tonci Mikac ] this paper the researcher proposed and assess algorithms and for regeneration manufacturing cell depending on G.A in this work they gloss over a new model that can be applied on system through rebuild the whole system in reverse way [Hatim \& etal ] in this work they present solution based on two basic steps first one assign basic product and their feature requirement and the second step reformation of manufacturing cell and also assort product based on their similar group. The proposed model has great flexibility to pick number of required cells which be more beneficial and important also they examine the work with other comparison study. [Mihajlović, I \& etal] this paper describe Genetic algorithms for planning layout optimization and material handling system and reduce the material the research shows close result for unique solution as comparison with other studies that will be in two stage depending on self-clustering arrangement of facilities in the first they present road map for organize the facility that applied on the plant also arrange the production process in the production cell will it collect the similar product in the relationship (machining relation) and the requirements for each product in the second stage they examine the algorithms on intercellular movement taking in consideration the different type constraint and technical standards 


\subsection{Problem Assignment}

Usually problems of designing layout take consideration of material to be handled and intercellular actions should be depend partmachine incidence matrix also its anticipated to form cells of machines in rapport to "distances" measured between them . these manufacturing cells are then modified by redistributing each part to its belong group where it machined ., Let

$$
A=\lambda_{i p}
$$

Where

$\lambda_{i p}$

\section{$\{1$ if part $p$ visit machine $i$ a step $t$ \\ \{ 0 if not}

If part $p$ take action on machines $i, j$ respectively

$\mu_{i p}=\left\{\begin{array}{c}1 \text { if } \mu_{i p} * \mu_{i p} \neq 0 \text { and }\left|\mu_{i p}-\mu_{p i}\right|=1 \\ 0 \quad \text { if not }\end{array}\right.$

Where $\mu_{i p}$ represent the constraint if the part will be machined at $\mathrm{i} \& \mathrm{j}$ in two stage or not . if we generalized the parts in all cells sections and machine

The objective function should be follow .

$$
\begin{aligned}
& \sum_{i=1}^{k-1} x_{i j}+\sum_{j=k+1}^{n} x_{k j} \leq M-1 \text { where } k \\
& =1 \text { to } n \\
& x_{i j}+x_{i k}-x_{k i} \leq 1 \text { where } i \\
& =1 \text { to } n-1 \\
& x_{i j}-x_{i k}-x_{k i} \leq 1 \text { where } j=i+1 \text { to } n-1 \\
& -x_{i j}-x_{i k}+x_{k i} \leq 1 \text { where } k \\
& =j+1 \text { to } n-1
\end{aligned}
$$

Constraint (3) organized traffic between machines when there are many machine $(M)$ at predefined cell and it also keeping behavior of sequences $(K)$. Constraints in (4) it obligate the incorruption of cells. These formulas take the most important issues, sequences of process and the product routs and allowed size for sections, The proposed case adjusted the revisiting product to the same machine must not be more than zero but some limits it should be taken in a count like volume weighting in the routings. For problem if the sections or whole layout sizes are fixed it can be considered as quadratic assignment transportation or If there are $\mathrm{k}$ cells of pre-specified sizes $m_{1}, \ldots \ldots m_{k}$ and $y_{i k}$ where $\mathrm{i}=1$ to $\mathrm{n} \&$ and $\mathrm{k}=1$ to $\mathrm{k}$ the binary parameters keep the $\mathrm{m}$ machines are allocated to cell $\mathrm{k}$ and could be connected with (6) in relations as below [16] .

$$
\begin{array}{r}
x_{i j}=\sum_{k=1}^{k} y_{i k} y_{j k} \text { where } i=1 \text { to } n-1 j \\
=i+1 \text { to } n-1 \ldots \ldots(6)
\end{array}
$$

\subsection{Implementation of a genetic algorithm .}

To implement the genetic algorithm its needed to clarify concept of problem and the requirements of implementation and environment of conditions that governs the optimization problem . Genetic algorithms are search heuristics that attempt to find an optimal solution based on a process of natural selection and evolution as it mentioned in the past of this work. The process involves generating random solutions and applying genetic operators in hopes that the solution will evolve to find the optimal solution.

\subsection{Parameters on optimization process}

After determining the problems, it's (5) desired to define parameters that affect on production process to get optimal solution. And then encode parameters to be used in solution of the problem in terms of chromosomes, genes, and populations. And applied it in the objective function 


\subsubsection{Representation.}

As it declared in previous, chromosomes represents a part of solution in the search space of the problem. Chromosome is just ordered list of sequences of operation in the manufacturing cell which each node is represented by its self, and gene is collection of chromosomes, a gene for the plant problem represent section and its location $(x, y)$ according the site of plant .

\subsubsection{Initial Population.}

Now create a set of children, and the offspring are erratically reprogrammed to create a new set of chromosomes to be reinserted into the population. In this case it should be take same plant situation. The production in plant is for going into four phases each operation place are decimal coded

I “27-28-14-36-26-37-25-24-23-22-2120-15-16-17"

II “27-34-32-33-35-24-23-22-21-15-16$17^{\prime \prime}$

III “'29-30-1-2-3-20-15-16-17

IV “27-13-11-12”

\subsubsection{Selection}

As it mentioned in the work of genetic algorithm procedure, Selection is one of the operators of genetic by picking parent of the plant operation status to regenerate the offspring .

\subsubsection{Crossover.}

After parents have been stated, the crossover operator mixed two chosen parents arbitrarily to produce two children chromosomes. In such case the crossover was done in multi stage which as known as multi-point crossover, because of four phases production process. which means each phase has suffered from mutation

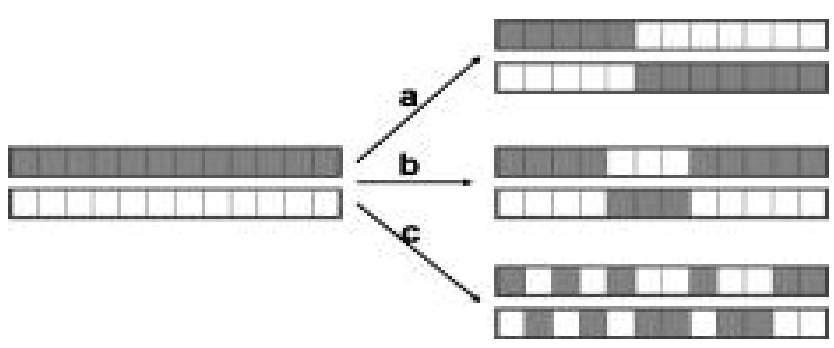

Figure 4.1 multi- point crossovers

\subsubsection{Mutation.}

The basics of genetic algorithms were build up to the degree of Mutation operation. This operation was done by changing gene value by another value under constraint of same phase of production process.

Before mutation

\begin{tabular}{|c|c|c|c|c|}
\hline IV & 27 & 13 & 11 & 12 \\
\hline \multicolumn{5}{|c|}{ After mutation } \\
\hline IV & 27 & 13 & 11 & 27 \\
\hline
\end{tabular}

\subsubsection{Convergence.}

The purpose of using convergence is to dispense huge populations and a large number of generations to enhancement the flexibility of algorithm by making benefits of parameters that used to reach the best constructed algorithm for finding best optimal solution. 


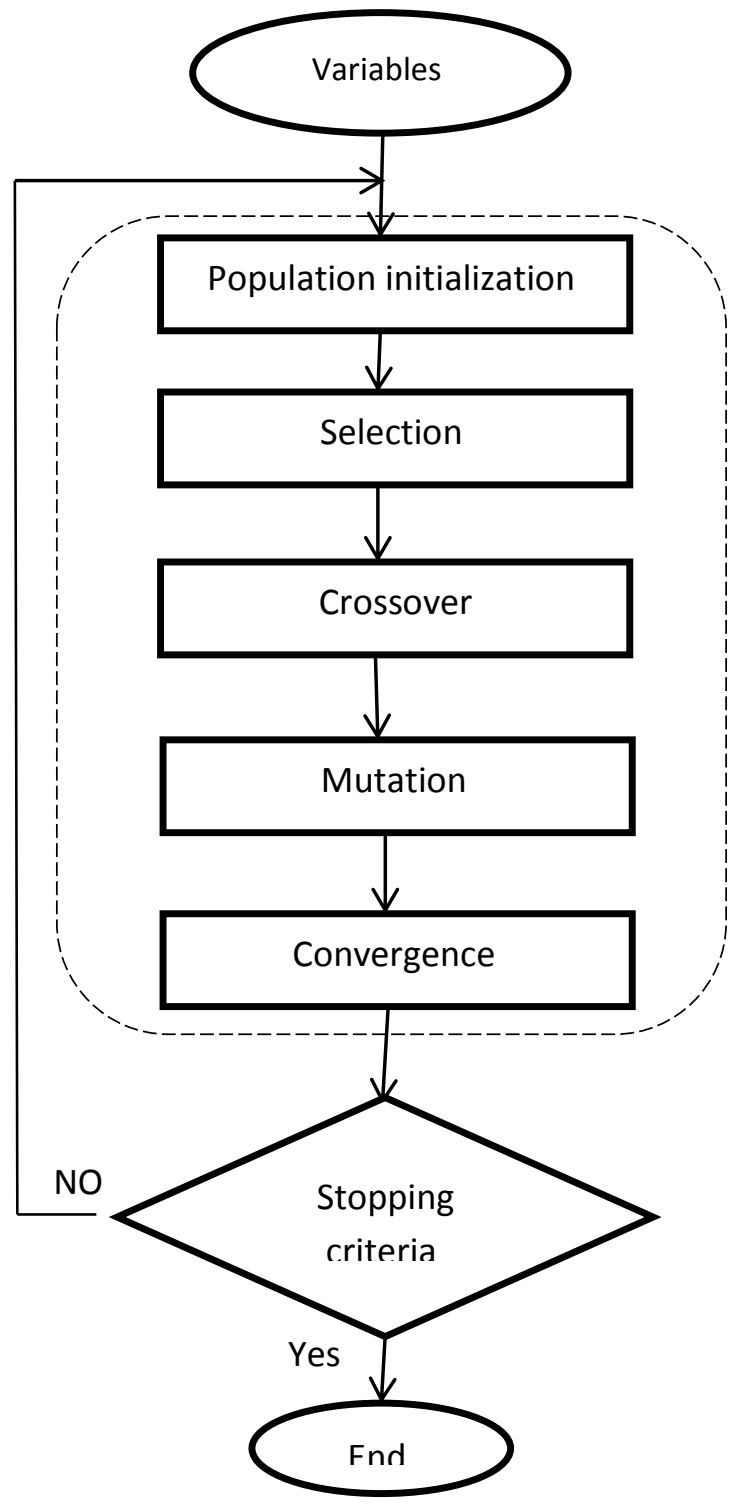

Figure 4.2 genetic algorithm

\subsection{Results}

The purpose of this section is to present and discuss some representative results of the work on the interaction genetic algorithms used in find the optimal design how they will affect on plant and route of the products cycle inside the product . First consider the product existing cycle inside the plant
Dhurgham .A / Maytham .S

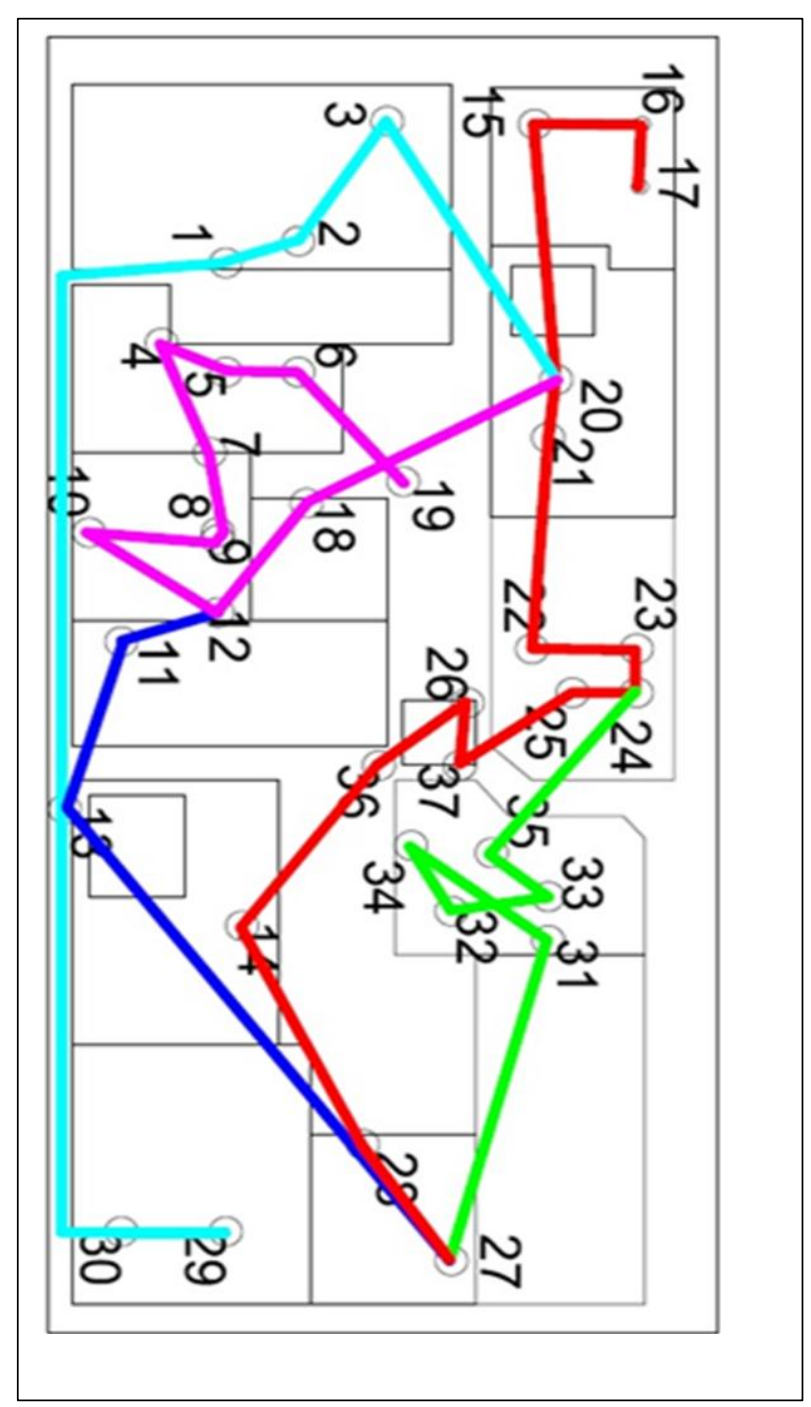

by using genetics showing how it will change the geography of the plant after using it

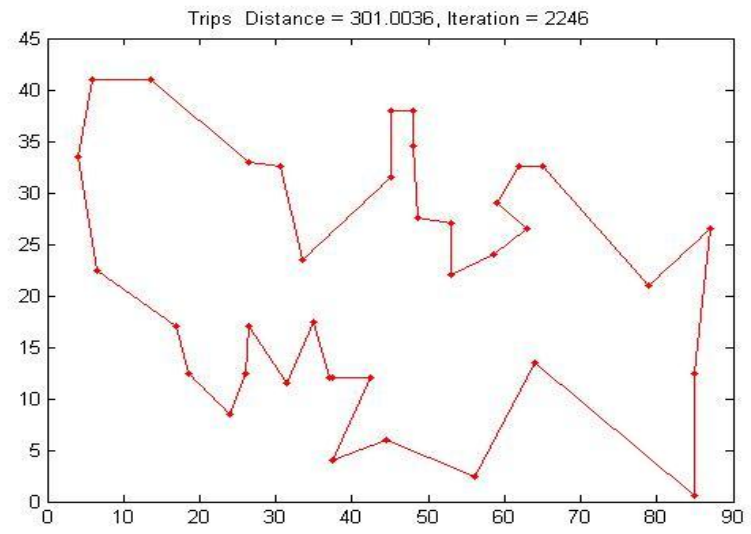

Figure 5.2 products for applying GA 
Dhurgham .A / Maytham .S
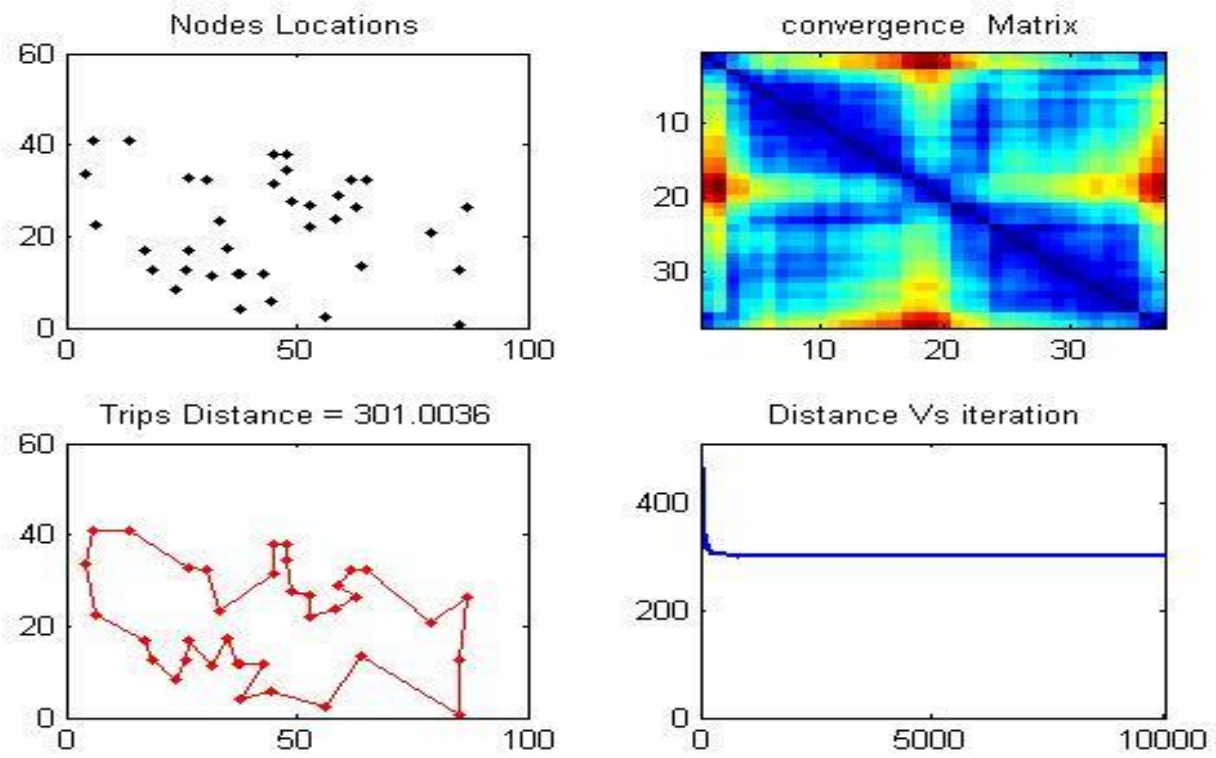

Figure 5.3 shows GA results

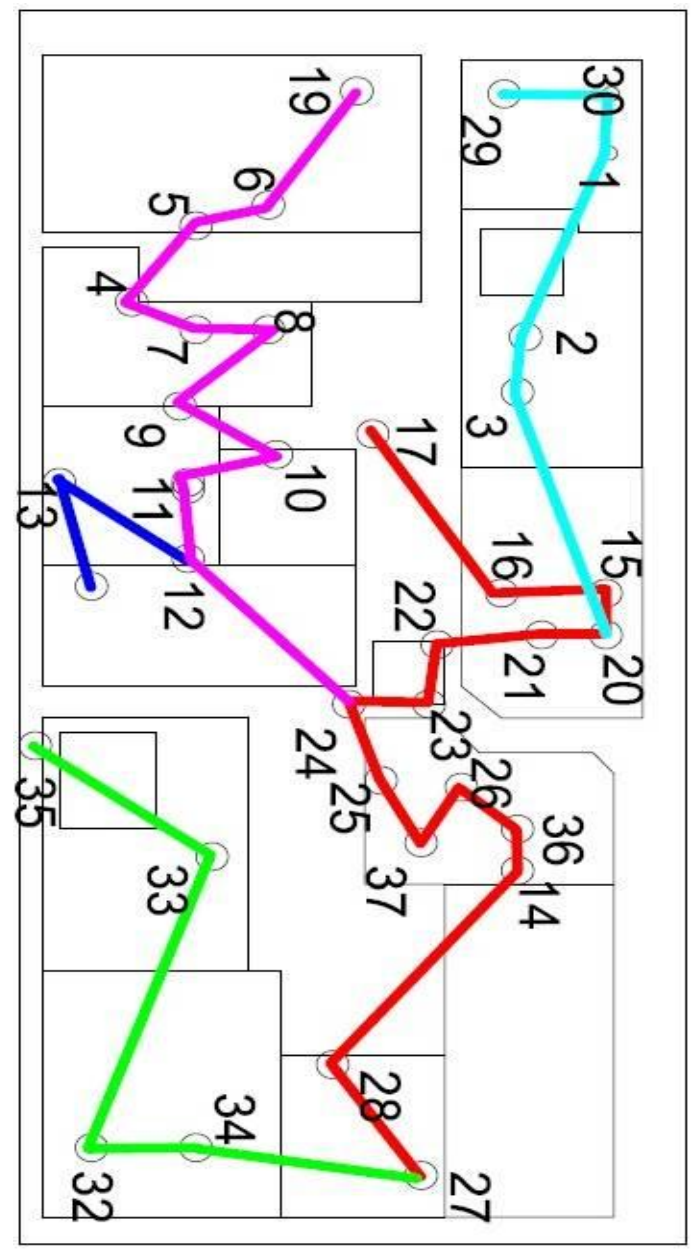

According to the result of work shown that the total distance should the products will travel about more than 800 meter inside the plant in addition there was home and away trips and that can be as multi-cycle before applying artificial work .

- The initialization scheme of algorithm must be accurate to maintain and state operation sequencing

- After monitoring the results and showing the site plan its significant to take in to account that the total distance that the products should cross about 301.0036 meter and iteration about 2246 (generation ) .the above

- Results discus the behavior of product and life cycle inside the plant and how it will change the road map for changing the way and the procedure of solution as below

Figure 5.4 the product life cycle inside sections of the plant after applying GA 


\subsection{Future Work .}

The contributions of this study may be further developed in several ways. Promising directions for future work are discussed in the following, separately for each part of the thesis .

- Enriched the algorithms with neural network and make a union algorithms works independently and extract best solution .

- Use GA to build update weight. And bias of neural network online in the plant parameters

- Rebuild ant colony algorithms dependent on genetic algorithm in such way that the genetic restructured the ant and swarm algorithms.

\section{References}

1. Sun, Liang, Xiaochun Cheng, and Yanchun Liang. "Solving job shop scheduling problem using genetic algorithm with penalty function." International Journal of Intelligent information processing 1 , no. 2 (2010): 65-77.

2. Car, Zlatan, and Tonci Mikac. "Evolutionary approach for solving cellformation problem in cell manufacturing." Advanced Engineering Informatics20, no. 3 (2006): 227-232.

3. Sharif, Hatim H., Khaled S. El-Kilany, and Mostafa A. Helaly. "A genetic algorithm approach to the group technology problem." In Proceedings of the International MultiConference of Engineers and Computer Scientists, vol. 2. 2008.

4. Mihajlović, I., Đ. Živković, and N. Štrbac. "Using genetic algorithms to resolve facility layout problem." Serbian Journal of Management 2, no. 1 (2007): 35-46.

5. Potočnik, Primož, Tomaž Berlec, Alojz Sluga, and Edvard Govekar. "Hybrid self-organization based facility layout planning." Strojniški vestnik-Journal of Mechanical Engineering 60, no. 12 (2014): 789-796.
6. Jannat, S., A. A. Khaled, and Sanjoy Kumar Paul. "Optimal solution for multi-objective facility layout problem using genetic algorithm." In Proc. 2010 Intl. Conference on Industrial Engineering and Operations Management. 2010.

7. El-Baz, M. Adel. "A genetic algorithm for facility layout problems of different manufacturing environments." Computers \& Industrial Engineering 47, no. 2 (2004): 233-246.

8. Saleh, Nur Fadhillah Binti, and Abdul Razak Bin Hussain. "Genetic Algorithms for Optimizing Manufacturing Facility Layout." (2008).

9. Ngampak, Nittaya, and Busaba Phruksaphanrat. "Cellular manufacturing layout design and selection: A case study of electronic manufacturing service plant." In Proceedings of the International Multi Conference of Engineers and Computer Scientists. 2011.

10. Krishnan, Krishna Kumar, Shokoufeh Mirzaei, Vijayaragavan Venkatasamy, and V. Madhusudanan Pillai. "A comprehensive approach to facility layout design and cell formation." The International Journal of Advanced Manufacturing Technology 59, no. 5-8 (2012): 737-753.

11. Hu, G. H., Y. P. Chen, Z. D. Zhou, and H. C. Fang. "A genetic algorithm for the inter-cell layout and material handling system design." The International Journal of Advanced Manufacturing Technology 34, no. 11 (2007): 11531163.

12. Cheng, Min-Yuan, and Li-Chuan Lien. "A hybrid AI-based particle bee algorithm for facility layout optimization." Engineering with Computers 28, no. 1 (2012): 57-69.

13. Yalaoui, Naim, Halim Mahdi, Lionel Amodeo, and Farouk Yalaoui. "A new approach for workshop design." Journal of Intelligent Manufacturing 22, no. 6 (2011): 933-951. 
14. Jithavech, Id, and Krishna Kumar Krishnan. "A simulation-based approach for risk assessment of facility layout designs under stochastic product demands." The International Journal of Advanced Manufacturing Technology 49, no. 1-4 (2010): 27-40.

15. Yang, Taho, and Brett A. Peters. "A spine layout design method for semiconductor fabrication facilities containing automated material-handling systems." International Journal of Operations \& Production Management 17, no. 5 (1997): 490-501.

16. Hamedi, M., N. Ismail, G. Esmaeilian, and M. Ariffin. "Virtual cellular manufacturing system based on resource element approach and analyzing its performance over different basic layouts." International Journal of Industrial Engineering Computations 3, no. 2 (2012): 265-276.

17. Ravichandran, K. S., K. Chandra Sekhara Rao, and R. Saravanan. "The role of fuzzy and genetic algorithms in part family formation and sequence optimisation for flexible manufacturing systems." The International Journal of Advanced Manufacturing Technology 19, no. 12 (2002): 879-888.

18. Narayanaswamy, Ramu. "STRATEGIC LAYOUT PLANNING AND SIMULATION FOR LEAN MANUFACTURING A LAYOPTTM TUTORIAL." Production Modeling Corporation (2002).

19. Cheng, Chun Hung, Chon-Huat Goh, and Anita Lee. "Solving the generalized machine assignment problem in group technology." Journal of the Operational Research Society 47, no. 6 (1996): 794802.

20. Chen, Zhi-Long. "Simultaneous job scheduling and resource allocation on parallel machines." Annals of Operations Research 129, no. 1 (2004): 135-153.
21. Shady, Ron, Gary Spake, and Brad Armstrong. "Simulation of a new product workcell." In Proceedings of the 29th conference on Winter simulation, pp. 739-743. IEEE Computer Society, 1997.

22. Liu, Lilan, Zhisong Shu, Xiaomei Hu, Xiangping $\mathrm{Hu}$, and Hongxia Cai. "Resource allocation and network evolution considering economics and robustness in manufacturing grid." The International Journal of Advanced Manufacturing Technology 57, no. 1 (2011): 393-410.

23. Nori, V. S., and B. R. Sarker. "Reducing work-in-process movement for multiple products in one-dimensional layout problems." Journal of the Operational Research Society 48, no. 4 (1997): 412 422.

24. Metts, Glenn A., and Charles H. Apigian. "Reducing manufacturing flow times: job shop simulation and reconfiguration." World Review of Business Research 1, no. 4 (2011): 97.

25. Metts, Glenn A., and Charles H. Apigian. "Reducing manufacturing flow times: job shop simulation and reconfiguration." World Review of Business Research 1, no. 4 (2011): 97.

26. Reddy, S. Narayana, V. Varaprasad, and V. Veeranna. "OPTIMIZATION OF MULTI-OBJECTVE FACILITY LAYOUT USING NONTRADITIONAL OPTIMIZATION TECHNIQUE." International Journal of Engineering Science and Technology 4, no. 2 (2012).

27. Kouvelis, Panagiotis, and Wen-Chyuan Chiang. "Optimal and heuristic procedures for row layout problems in automated manufacturing systems." Journal of the Operational Research Society 47, no. 6 (1996): 803 816. 


$$
\text { ميثم سلمان عزيز }
$$

maytham.jebory@gmail.com
ضرغام ايهم كاظم

durghamalshakerchi@gmail.com

كلية الكفيل الجامعةـ قسم هندة تقنيات الحاسوب

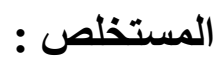

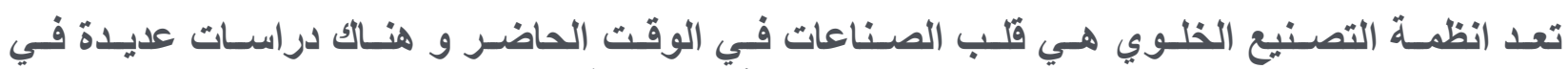

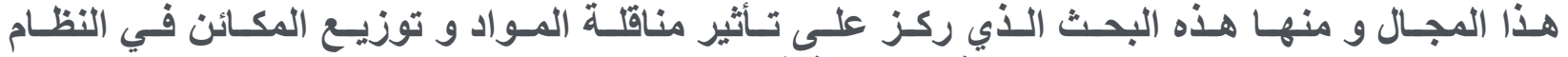

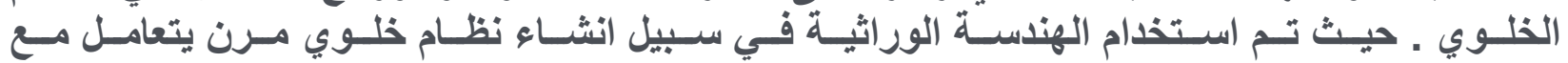

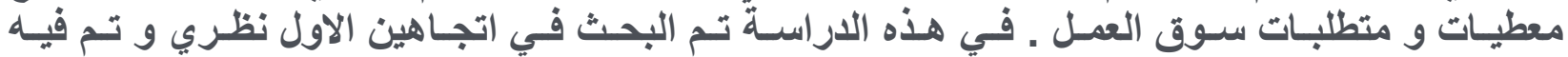

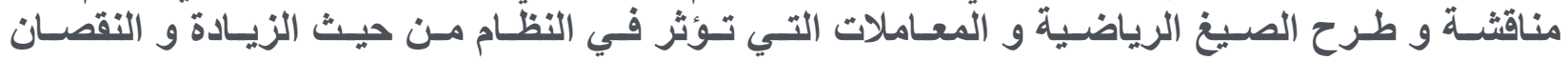

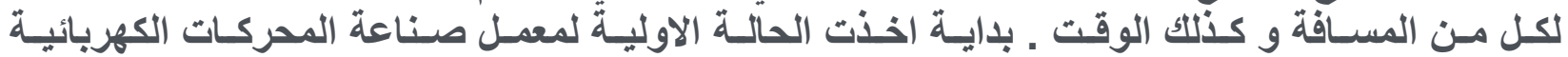

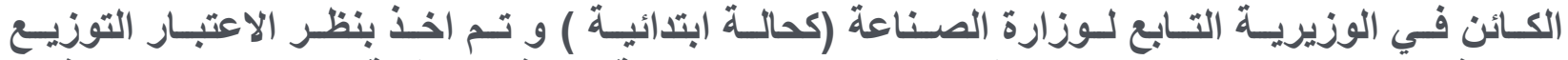

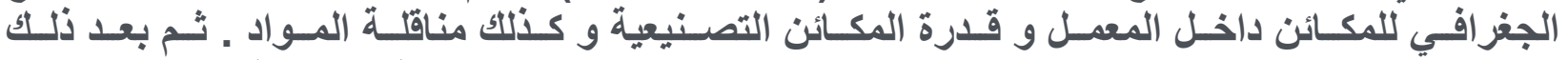

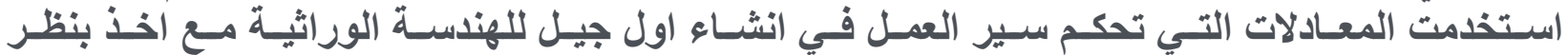

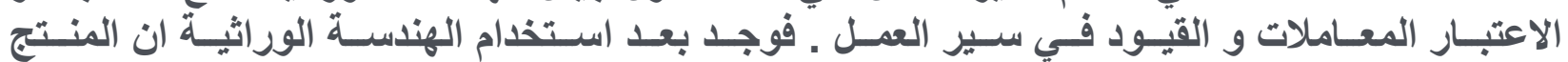

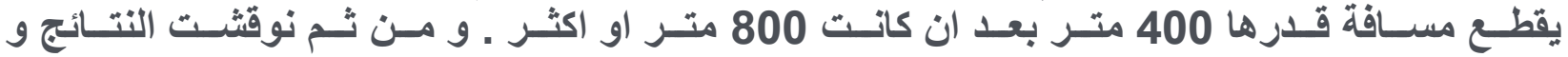

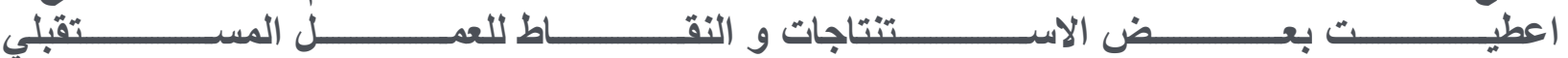

